\title{
Association between maternal depression and anxiety episodes and rates of childhood injuries: a cohort study from England
}

\author{
Ruth Baker \\ Division of Primary Care, University of Nottingham, Nottingham, United Kingdom. Telephone: +44 \\ (0)115 846 6900. Fax: +44 (0) 115846 6904. Email: ruth.baker@nottingham.ac.uk
}

Denise Kendrick

Division of Primary Care, University of Nottingham, Nottingham, United Kingdom. denise.kendrick@nottingham.ac.uk

Laila J Tata

Division of Epidemiology and Public Health, University of Nottingham, Nottingham, United Kingdom.

laila.tata@nottingham.ac.uk

Elizabeth Orton

Division of Primary Care, University of Nottingham, Nottingham, United Kingdom. elizabeth.orton@nottingham.ac.uk

*Corresponding author

Key words: child, injury, mental health, burn, poisoning, cohort study

Word count: 3000 


\section{ABSTRACT}

Background. Maternal depression is common and associated with several child health outcomes. The impact on childhood injuries is underexplored, with existing studies relying on maternal reporting of injury occurrences. Using population healthcare databases from England, we assessed the association between maternal depression and/or anxiety episodes and rates of child poisonings, fractures, burns and serious injuries.

Methods. We conducted a prospective cohort study of 207,048 mother-child pairs with linked primary care and hospitalisation data from the Clinical Practice Research Datalink and Hospital Episode Statistics, 1998-2013. Episodes of maternal depression and/or anxiety were identified using diagnoses, prescriptions and hospitalisations, with the child's follow-up time divided into exposed and unexposed periods. Adjusted incidence rate ratios (aIRR) for child injury during maternal mental health episodes were estimated using Poisson regression.

Results. 54,702 children (26.4\%) were exposed to maternal depression and/or anxiety when aged 04 years. During follow-up 2,614 poisonings, 6,088 fractures and 4,201 burns occurred. Child poisoning rates increased during episodes of maternal depression (aIRR 1.52, 95\% confidence interval 1.31-1.76), depression with anxiety $(2.30,1.93-2.75)$ and anxiety alone $(1.63,1.09-2.43)$. Similarly, rates of burns $(1.53,1.29-1.81)$ and fractures $(1.24,1.06-1.44)$ were greatest during depression with anxiety episodes. There was no association between maternal depression and/or anxiety and serious child injuries.

Conclusions. Maternal depression and/or anxiety episodes were associated with increased rates of child poisonings, fractures and burns. Whilst mechanisms are unclear, prompt identification and 
treatment of maternal depression and/or anxiety and provision of safety advice (e.g. safe medication storage) may reduce child injury risk. 


\section{INTRODUCTION}

Mental illnesses are the commonest morbidity women experience during pregnancy and the postnatal period,[1] and have been associated with a number of short and long term consequences for the health and wellbeing of the child,[2] including some literature suggesting an association with childhood injuries.[3-5] Preventing childhood injuries is a priority both within the United Kingdom (UK) and worldwide[6 7] since injuries are a leading cause of death, ill health and disability in children,[7] and result in substantial costs to health services and society.[8] Several studies have demonstrated associations between maternal depression and childhood injuries,[3-5 910$]$ with most focusing on maternal depression alone,[3-5 9 10] relying on maternal reporting of child injuries[3-5], and often using single measures of maternal depression, which may not accurately reflect the changing nature of depression over time (i.e. remission, relapses). To extend the findings of existing studies, we investigated the association between maternal depression and/or anxiety episodes and rates of child poisonings, fractures, burns and serious injuries using a large cohort of mother-child pairs from England with linked primary care and hospitalisation data. Specifically, we firstly aimed to take account of the fluctuating nature of maternal depression and/or anxiety (termed 'depression/anxiety') during the child's first five years of life by using maternal depression/anxiety episodes as a time-varying exposure. Secondly, we aimed to examine whether associations differed if mothers had comorbid depression with anxiety compared to depression or anxiety alone. 


\section{METHODS}

\section{Data sources}

We used two population based health databases from England; the Clinical Practice Research Datalink (CPRD) and Hospital Episode Statistics (HES). The CPRD is one of the largest primary care research databases in the world, containing the primary care records of over 11 million patients from the UK.[11] Approximately $6.9 \%$ of the population are included in the database, with patients broadly representative of the population by age, sex and ethnicity.[11] The CPRD contains information about patient diagnoses, lifestyle factors, prescriptions, and correspondence from secondary and tertiary care (e.g. outpatient clinics, emergency department attendances). General practitioners (GPs) record information in the primary care record using Read codes, a hierarchical coding system based on the International Classification of Diseases (ICD-10).[12] The HES dataset captures all hospitalisations in England paid for by the National Health Service, with diagnostic information recorded using ICD-10.

\section{Study population}

We identified a cohort of children from the CPRD who were born between 1st January 1998 and 31st December 2013, whose primary care records had been linked to those of their mother, and for whom linked hospitalisation data (HES) were available. Children were linked to their mothers by the CPRD based on family and practice identifiers, and information contained in the mother's records about pregnancy and delivery. To be included in the cohort, children had to be registered with their GP within 3 months of birth to maximise capture of early medically attended injuries, and mothers had to contribute to the CPRD for six months prior to pregnancy to capture maternal depression/anxiety episodes starting prior to, or during pregnancy that may have continued after delivery. One child was randomly selected per mother to minimise the impact of clustering of risk factors within families. 
Children were followed up from birth to the earliest of: their fifth birthday, the $31^{\text {st }}$ December 2013 (end of study period), the date information was last collected from the practice, or the date mother or child left the practice (i.e. died, deregistered). If a mother was diagnosed with a serious mental illness (bipolar disorder or schizophrenia) during study follow-up, the mother-child pair was censored at this date.

\section{Maternal depression and/or anxiety episodes}

We identified all records for depression/anxiety recorded in the mother's primary care (CPRD) and hospitalisation (HES) records, using Read and ICD-10 code lists respectively (supplementary file 1). We included Read codes for symptoms (e.g. 1BT..11 Low Mood) and diagnoses (e.g. Eu33100 Recurrent depressive disorder), as GPs have increasingly used symptom codes to record depression[13] and anxiety[14] over time. We identified prescriptions for antidepressants and anxiolytics from the CPRD, estimating the duration of prescription from information on the dose, quantity prescribed and dosing instructions. We excluded antidepressant courses for indications other than depression/anxiety (e.g. migraine prophylaxis) by; firstly examining diagnoses recorded at the start of the course to identify an indication for the medication, secondly excluding prescriptions for low dose Amitriptyline $(<75 \mathrm{mg})$, and thirdly excluding prescriptions where the mother had no history of depression/anxiety and no diagnosis within the following six months.

The start of a depression/anxiety episode was defined by the presence of a diagnostic, symptom, hospitalisation or prescription record for depression/anxiety, with the episode considered to have ended if no further records for depression/anxiety were recorded in the subsequent six months. Any records or prescriptions for depression/anxiety occurring more than six months after the previous record were considered the start of a new episode. Episodes of depression with anxiety were defined in two ways; firstly by the presence of specific Read or ICD-10 codes that specified both depression and anxiety (e.g. E200300 Anxiety with depression), and secondly by concurrent 
recording of both anxiety and depression records within the same episode (using six month timewindow).

\section{Child injuries}

Incident poisonings, fractures and burns occurring during the child's follow-up were identified from the child's primary care and/or hospitalisation records, as previously described.[15] We focused on poisonings, fractures and burns as they are three of the commonest injuries in children aged 0-4 years old and are a priority for prevention.[6] As children may have multiple records for the same injury event, either due to the same injury being recorded in both data sources or there being multiple records as a result of follow-up care, an algorithm was used to exclude repeated records for the same injury event.[15] This enabled the inclusion of repeated injury events per child.

We defined a group of serious child injuries (e.g. femur fractures, third degree burns), based upon previous definitions,[16 17 [ $]$ that should always lead to hospitalisation (supplementary file 1). As such, ascertainment of these events should be unaffected by differences in health service use by mothers, hospital admission thresholds or recording practices of clinicians.

\section{Statistical analyses}

Maternal depression/anxiety episodes were used as a time-varying exposure, with the child's followup time divided into exposed (maternal depression/anxiety episodes) and unexposed periods (Figure 1). Incidence rates of poisonings, fractures, burns and serious injuries were calculated by dividing the number of injury events by the sum of the person-years at risk, according to exposure to maternal depression/anxiety. Unadjusted and adjusted incidence rate ratios (aIRR), with 95\% confidence intervals $(95 \% \mathrm{Cl})$ were estimated using Poisson regression. Socioeconomic deprivation (measured using quintiles of the Index of Multiple Deprivation 2010), calendar year and region were considered a priori confounders. Region and calendar year were included to take account of potential 
differences in clinical coding by region and over time. Other variables in the dataset were child age at injury, child sex, maternal age at delivery, numbers of older siblings and numbers of children aged 0-4 years in the household. Potential confounders were included in the final model if they changed the IRR by $10 \%$ or more. Likelihood ratio tests (LRT) were used to assess the significance of associations, with $p<0.05$ considered statistically significant. An interaction between maternal depression/anxiety and socioeconomic deprivation was assessed by adding interaction terms into the Poisson regression models, with $p<0.01$ considered statistically significant.

\section{Sensitivity analyses}

We conducted four sensitivity analyses. The first extended the time-window used to define episodes of depression/anxiety from six to twelve months; meaning that for children whose mothers had repeated depression/anxiety records, more of their follow-up time was classified as being 'exposed'. The second excluded symptom codes from the definition of depression/anxiety (Supplementary file 1). The third completely excluded mothers diagnosed with serious mental illnesses during study follow-up, as these mothers may have started to develop symptoms of the serious mental illness before the diagnosis was made. The fourth sensitivity analysis excluded child injuries likely to be due to intentional harm; identified using Read and ICD-10 codes for intentional injury, assault, and concerns about maltreatment[18] (Supplementary file 1).

Study approval was granted by the Independent Scientific Advisory Committee for the Medicines and Healthcare products Regulatory Agency, February 2014 (protocol 14_025R). All analyses were conducted using Stata 13. 


\section{RESULTS}

The study cohort consisted of 207,048 mother-child pairs (Table 1). Of the children, 159,787 (51.2\%) were male and 152,129 (48.8\%) were female. Median follow-up from birth was 3.9 years (interquartile range 1.6-5.0). Children from the most deprived areas were underrepresented in the study cohort (17.2\%) whereas those from the most affluent areas were slightly overrepresented (22.7\%). Most children were registered with a GP within a month of birth ( $n=132,679,64.1 \%)$.

\section{Maternal depression/anxiety episodes}

Of the mothers, 54,702 (26.4\%) experienced one or more depression/anxiety episodes between the child's birth and end of follow-up. Most depression ( $n=32,354,64.2 \%)$ and depression with anxiety $(n=8,616,81.1 \%)$ episodes were defined by Read codes and antidepressant prescriptions (supplementary file 2). Comparatively, anxiety episodes were most commonly defined by Read codes alone $(n=6,967,53.4 \%)$. Compared to episodes of depression $(n=1,075,2.1 \%)$, a higher proportion of depression with anxiety episodes were defined by Read code, prescription and hospital admission records ( $n=1,065,10.0 \%)$.

\section{Child injury rates during maternal depression/anxiety episodes}

During study follow-up, 2,614 poisonings, 6,088 fractures, 4,201 burns and 915 serious injuries occurred amongst the cohort of children. Crude poisoning, fracture and burn incidence rates were higher during episodes of maternal depression, depression with anxiety and anxiety alone compared to unexposed periods (Table 2). 
Table 1: Characteristics of mother-child cohort, children born between the 1st January 1998 and 31st December 2013

\begin{tabular}{|c|c|}
\hline & Frequency (\%) \\
\hline \multicolumn{2}{|l|}{ Child sex } \\
\hline Male & $105,958(51.2)$ \\
\hline Female & $101,090(48.8)$ \\
\hline \multicolumn{2}{|c|}{ Age of child at start of follow-up (months) ${ }^{a}$} \\
\hline$<1$ & $132,679(64.1)$ \\
\hline $1-2$ & $62,558(30.2)$ \\
\hline 2-3 & $11,811(5.7)$ \\
\hline \multicolumn{2}{|c|}{ Maternal age at delivery (years) } \\
\hline$<20$ & $9,575(4.6)$ \\
\hline $20-29$ & $80,481(38.9)$ \\
\hline 30-39 & $107,707(52.0)$ \\
\hline$\geq 40$ & $9,285(4.5)$ \\
\hline \multicolumn{2}{|c|}{ Socioeconomic deprivation, IMD $2010^{\mathrm{b}}$} \\
\hline Quintile 1 (least deprived) & $47,010(22.7)$ \\
\hline Quintile 2 & $43,699(21.1)$ \\
\hline Quintile 3 & $39,674(19.2)$ \\
\hline Quintile 4 & $40,728(19.7)$ \\
\hline Quintile 5 (most deprived) & $35,658(17.2)$ \\
\hline Missing & $279(0.1)$ \\
\hline \multicolumn{2}{|c|}{ Maternal alcohol misuse during study follow-up } \\
\hline No & $202,666(97.9)$ \\
\hline Yes & $4,382(2.1)$ \\
\hline \multicolumn{2}{|c|}{ Maternal drug misuse during study follow-up } \\
\hline No & $205,888(99.4)$ \\
\hline Yes & $1,160(0.6)$ \\
\hline \multicolumn{2}{|c|}{ Total number of children aged $<5$ in the household } \\
\hline 1 & $95,558(46.2)$ \\
\hline 2 & $88,462(42.7)$ \\
\hline 3 & $18,080(8.7)$ \\
\hline 4 or more & $4,948(2.4)$ \\
\hline \multicolumn{2}{|c|}{ Number of older siblings/children } \\
\hline 0 & $81,738(39.5)$ \\
\hline 1 & $80,162(38.7)$ \\
\hline 2 & $30,353(14.7)$ \\
\hline 3 or more & $14,795(7.2)$ \\
\hline
\end{tabular}

${ }^{a}$ to be included in the study population children had to start follow-up within 3 months of birth to maximise capture of early injury events.

bIndex of Multiple Deprivation 2010, based on residential postcode of child/family 
Maternal depression/anxiety episodes were significantly associated with child poisonings $(p<0.0001)$, fractures $(p=0.005)$ and burns $(p<0.0001)$, but not with serious injuries $(p=0.47)$. The strongest association was seen for child poisonings. Children had a $52 \%$ higher poisoning rate during maternal depression episodes (aIRR 1.52, 95\% Cl 1.31-1.76), a two-fold higher poisoning rate during depression with anxiety episodes (aIRR $2.30,95 \% \mathrm{Cl} 1.93-2.75$ ) and a $63 \%$ higher poisoning rate during anxiety episodes (aIRR $1.63,95 \% \mathrm{Cl} 1.09-2.43$ ) compared to unexposed periods. Similarly, rates of burns and fractures were greatest during episodes of maternal depression with anxiety, with rates $53 \%$ (aIRR $1.53,95 \% \mathrm{Cl} 1.29-1.81$ ) and $24 \%$ (aIRR 1.06-1.44) higher compared to unexposed periods, respectively. Incidence rates of serious injuries were highest during episodes of maternal depression $(16.8 / 10,000,95 \% \mathrm{Cl} 12.9-21.9)$, but this was not significant in unadjusted or adjusted models. There were no significant interactions between maternal depression/anxiety episodes and socioeconomic deprivation for any of the four injury types ( $p=0.93$ poisonings, $p=0.02$ fractures, $p=0.48$ burns, $p=0.1$ serious injuries).

\section{Sensitivity analyses}

Extending the time-window used to define maternal depression/anxiety episodes from six to twelve months led to small increases in the magnitude of adjusted IRRs, but did not change study conclusions for poisonings, fractures or burns (Table 3). The magnitude of association between maternal depression/anxiety episodes and serious injuries however increased, although was still not statistically significant $(p=0.1)$. The exclusion of symptom codes from the definition of depression/anxiety led to small changes in the adjusted IRRs, with rates of fractures no longer elevated during depression with anxiety episodes compared to unexposed periods (IRR $1.10,95 \% \mathrm{Cl}$ 0.90-1.33). Adjusted IRR were similar to the primary analysis following the exclusion of mother-child pairs where the mother was diagnosed with a serious mental illness $(n=219)$, and the exclusion of injuries that may have been due to intentional harm (15 poisonings, 62 fractures, 33 burns and 48 serious injuries). 
Table 2: Unadjusted and adjusted incidence rate ratios for the association between maternal depression/anxiety episodes and child injuries

\begin{tabular}{|c|c|c|c|c|c|c|c|}
\hline & & $\begin{array}{l}\text { Incident injury } \\
\text { events }\end{array}$ & Person-years & $\begin{array}{l}\text { Crude incidence rate } \\
\text { per } 10,000 \text { person- } \\
\text { years }(95 \% \mathrm{Cl})\end{array}$ & $\begin{array}{l}\text { Unadjusted incidence } \\
\text { rate ratio } \\
(95 \% \mathrm{Cl})\end{array}$ & $\begin{array}{l}\text { Adjusted incidence } \\
\text { rate ratio } \\
(95 \% \mathrm{Cl}) \\
\end{array}$ & $p$ value $^{b}$ \\
\hline \multirow[t]{4}{*}{ POISONINGS } & Unexposed & 2,276 & 635,195 & $35.8(34.4-37.3)$ & 1 & 1 & \multirow{4}{*}{$<0.0001$} \\
\hline & Depression & 186 & 32,127 & $57.9(50.1-66.8)$ & $1.62(1.39-1.88)$ & $1.52(1.31-1.76)$ & \\
\hline & Depression with anxiety & 128 & 14,727 & $86.9(73.1-103.4)$ & $2.43(2.03-2.90)$ & $2.30(1.93-2.75)$ & \\
\hline & Anxiety & 24 & 4,053 & $59.2(39.7-88.3)$ & $1.65(1.11-2.47)$ & $1.63(1.09-2.43)$ & \\
\hline \multirow[t]{4}{*}{ FRACTURES } & Unexposed & 5,560 & 635,195 & $87.5(85.3-89.9)$ & 1 & 1 & \multirow{4}{*}{0.005} \\
\hline & Depression & 331 & 32,127 & $103.0(92.5-114.7)$ & $1.18(1.05-1.32)$ & $1.15(1.03-1.28)$ & \\
\hline & Depression with anxiety & 165 & 14,727 & $112.0(96.2-130.5)$ & $1.28(1.10-1.49)$ & $1.24(1.06-1.44)$ & \\
\hline & Anxiety & 32 & 4,053 & $79.0(55.8-111.6)$ & $0.90(0.64-1.28)$ & $0.87(0.61-1.23)$ & \\
\hline \multirow[t]{4}{*}{ BURNS } & Unexposed & 3,773 & 635,195 & $59.4(57.5-61.3)$ & 1 & 1 & \multirow{4}{*}{$<0.0001$} \\
\hline & Depression & 254 & 32,127 & $79.0(69.9-89.4)$ & $1.33(1.17-1.51)$ & $1.31(1.15-1.48)$ & \\
\hline & Depression with anxiety & 139 & 14,727 & $94.4(79.9-111.4)$ & $1.59(1.34-1.88)$ & $1.53(1.29-1.81)$ & \\
\hline & Anxiety & 35 & 4,053 & $86.4(62.0-120.3)$ & $1.45(1.04-2.03)$ & $1.47(1.05-2.05)$ & \\
\hline \multirow{4}{*}{$\begin{array}{l}\text { SERIOUS } \\
\text { INJURIES }\end{array}$} & Unexposed & 837 & 635,195 & $13.2(12.3-14.1)$ & 1 & 1 & \multirow{4}{*}{0.47} \\
\hline & Depression & 54 & 32,127 & $16.8(12.9-21.9)$ & $1.28(0.97-1.68)$ & $1.25(0.95-1.65)$ & \\
\hline & Depression with anxiety & 19 & 14,727 & $12.9(8.2-20.2)$ & $0.98(0.62-1.54)$ & $0.95(0.60-1.50)$ & \\
\hline & Anxiety & 5 & 4,053 & $12.3(5.1-29.6)$ & $0.94(0.39-2.26)$ & $0.95(0.39-2.29)$ & \\
\hline
\end{tabular}

a adjusted for a priori confounders, calendar year, region and socioeconomic deprivation. None of the other potential confounders were included in the final model, as none led to a $\geq 10 \%$ change in the incidence rate ratio when added to the model.

b likelihood ratio test 
Table 3: Sensitivity analyses, cohort analysis of the association between maternal depression/anxiety episodes and child injuries

\begin{tabular}{|c|c|c|c|c|c|c|c|}
\hline & & & $\begin{array}{c}\text { Primary } \\
\text { analysis } \\
(\mathrm{n}=\mathbf{2 0 7 , 0 4 8 )}\end{array}$ & $\begin{array}{l}\text { Doubling time-window to } \\
\text { define depression/anxiety } \\
\text { episodes }(n=207,048)\end{array}$ & $\begin{array}{l}\text { Excluding symptom codes } \\
\text { from depression/anxiety } \\
\text { definition }(n=207,048)\end{array}$ & $\begin{array}{l}\text { Excluding mothers with } \\
\text { serious mental illnesses } \\
\qquad(n=206,829)\end{array}$ & $\begin{array}{l}\text { Excluding likely } \\
\text { intentional injuries } \\
(n=207,048)\end{array}$ \\
\hline \multirow[t]{5}{*}{ POISONINGS } & \multicolumn{2}{|c|}{ Number of incident poisonings } & 2,614 & 2,614 & 2,614 & 2,611 & 2,599 \\
\hline & \multirow{4}{*}{$\begin{array}{l}\text { Adjusted IRR \# } \\
(95 \% \mathrm{CI})\end{array}$} & Unexposed & 1 & 1 & 1 & 1 & 1 \\
\hline & & Depression & $1.52(1.31-1.76)$ & $1.55(1.33-1.79)$ & $1.54(1.33-1.78)$ & $1.51(1.30-1.76)$ & $1.49(1.28-1.74)$ \\
\hline & & $\begin{array}{l}\text { Depression } \\
\text { with anxiety }\end{array}$ & $2.30(1.93-2.75)$ & $2.37(2.03-2.76)$ & $2.27(1.85-2.79)$ & $2.28(1.91-2.73)$ & $2.32(1.94-2.77)$ \\
\hline & & Anxiety & $1.63(1.09-2.43)$ & $1.67(1.12-2.47)$ & $2.04(1.46-2.87)$ & $1.63(1.09-2.44)$ & $1.57(1.04-2.36)$ \\
\hline \multirow[t]{5}{*}{ FRACTURES } & \multicolumn{2}{|c|}{ Number of incident fractures } & 6,088 & 6,088 & 6,088 & 6,085 & 6,026 \\
\hline & \multirow{4}{*}{$\begin{array}{l}\text { Adjusted IRR \# } \\
(95 \% \mathrm{Cl})\end{array}$} & Unexposed & 1 & 1 & 1 & 1 & 1 \\
\hline & & Depression & $1.15(1.03-1.28)$ & $1.19(1.07-1.33)$ & $1.16(1.04-1.29)$ & $1.15(1.03-1.28)$ & $1.14(1.02-1.28)$ \\
\hline & & $\begin{array}{l}\text { Depression } \\
\text { with anxiety }\end{array}$ & $1.24(1.06-1.44)$ & $1.20(1.05-1.37)$ & $1.10(0.91-1.33)$ & $1.25(1.07-1.45)$ & $1.23(1.05-1.43)$ \\
\hline & & Anxiety & $0.87(0.61-1.23)$ & $0.97(0.71-1.35)$ & $1.19(0.90-1.57)$ & $0.84(0.59-1.20)$ & $0.87(0.62-1.24)$ \\
\hline \multirow[t]{5}{*}{ BURNS } & \multicolumn{2}{|c|}{ Number of incident burns } & 4,201 & 4,201 & 4,201 & 4,196 & 4,168 \\
\hline & \multirow{4}{*}{$\begin{array}{l}\text { Adjusted IRR \# } \\
(95 \% \mathrm{CI})\end{array}$} & Unexposed & 1 & 1 & 1 & 1 & 1 \\
\hline & & Depression & $1.31(1.15-1.48)$ & $1.28(1.13-1.45)$ & $1.31(1.15-1.48)$ & $1.31(1.16-1.49)$ & $1.28(1.13-1.46)$ \\
\hline & & $\begin{array}{l}\text { Depression } \\
\text { with anxiety }\end{array}$ & $1.53(1.29-1.81)$ & $1.60(1.38-1.84)$ & $1.53(1.26-1.86)$ & $1.51(1.28-1.80)$ & $1.52(1.29-1.81)$ \\
\hline & & Anxiety & $1.47(1.05-2.05)$ & $1.60(1.16-2.19)$ & $1.51(1.11-2.05)$ & $1.47(1.05-2.05)$ & $1.39(0.99-1.96)$ \\
\hline \multirow{5}{*}{$\begin{array}{l}\text { SERIOUS } \\
\text { INJURIES }\end{array}$} & \multicolumn{2}{|c|}{ Number of serious injuries } & 915 & 915 & 915 & 913 & 867 \\
\hline & \multirow{4}{*}{$\begin{array}{l}\text { Adjusted IRR \# } \\
(95 \% \mathrm{Cl})\end{array}$} & Unexposed & 1 & 1 & 1 & 1 & 1 \\
\hline & & Depression & $1.25(0.95-1.65)$ & $1.39(1.08-1.80)$ & $1.20(0.91-1.59)$ & $1.26(0.96-1.67)$ & $1.30(0.99-1.72)$ \\
\hline & & $\begin{array}{l}\text { Depression } \\
\text { with anxiety }\end{array}$ & $0.95(0.60-1.50)$ & $1.15(0.81-1.65)$ & $0.86(0.50-1.49)$ & $0.96(0.61-1.51)$ & $0.90(0.56-1.46)$ \\
\hline & & Anxiety & $0.95(0.39-2.29)$ & $0.93(0.39-2.24)$ & $1.49(0.77-2.88)$ & $0.95(0.40-2.30)$ & $0.80(0.30-2.14)$ \\
\hline
\end{tabular}

\# adjusted for a priori confounders, calendar year, region and socioeconomic deprivation 


\section{DISCUSSION}

This study demonstrated increased incidence rates of child poisonings, fractures and burns during episodes of maternal depression/anxiety among a cohort of over 200,000 mother-child pairs from England. The greatest increase was for rates of poisonings, which were $230 \%$ higher during maternal depression with anxiety episodes, 63\% higher during anxiety episodes, and 52\% higher during depression episodes. Similar to poisonings, rates of child fractures and burns were highest during maternal depression with anxiety episodes. No association was observed between maternal depression/anxiety and rates of serious injuries. While this study does not demonstrate causality, these observed associations suggest maternal depression/anxiety may be an important modifiable risk factor for childhood injuries.

\section{Strengths and limitations}

Key strengths of this study include the large sample size, and use of linked primary care and hospitalisation data to identify maternal depression/anxiety episodes and the occurrence of child injuries. As symptoms of maternal depression/anxiety fluctuate over time, with some mothers experiencing remission and relapses, the use of depression/anxiety episodes as a time-varying exposure is a key strength of the study, allowing more accurate assessment of the timing of childhood injuries in relation to the occurrence of medically recorded episodes of maternal depression/anxiety. In addition, as most data held within primary care and hospitalisation records are prospectively recorded, our results are less likely to be affected by social desirability and response biases associated with self-reported data in questionnaire studies.

Our study however has several potential limitations. Firstly, by using mothers' medical records to define depression/anxiety we only identified depression/anxiety episodes where mothers sought medical care and where information was recorded in the medical record. As such, underreporting of mental illnesses, alongside inaccuracies in estimated start and end dates of depression/anxiety 
episodes mean our results are likely to be underestimates as a result of misclassification of some follow-up time as unexposed.[19-21] In addition, similar to other studies[21 22] it was not possible to assess the severity of depression/anxiety or how symptom severity changed in response to antidepressant and/or anxiolytic treatment.

Secondly, some of our findings could be explained by differences in healthcare use by mothers and/or the recording of injuries by clinicians (e.g. surveillance bias) according to whether mothers have a mental illness or not. For example, associations between maternal depression/anxiety and child injuries may be overestimated if mothers with depression/anxiety are more likely to seek medical care for minor injuries. Reduction in ascertainment bias may be one explanation for the lack of association seen between maternal depression/anxiety and serious child injuries (e.g. skull fractures, multiple rib fractures), where ascertainment should be complete; although this absence of association may also be explained by less study power (smaller numbers of events), and potential differences in the effect of maternal depression/anxiety according to injury severity (e.g. greater awareness and recognition of preventing serious injuries amongst mothers[23]).

Thirdly, while CPRD-HES data broadly represent the demographics of the UK population[11] there is some underrepresentation of those from the most deprived areas in the cohort. As a result we may have underestimated the association between maternal depression/anxiety and child injuries if some of the most vulnerable mother-child pairs (e.g. those frequently moving house or GP) were excluded from the study population.

Finally, we were unable to adjust for some potential confounders, such as single parenthood, social support, paternal risk factors or parenting practices, as routine health data do not capture this information. Residual confounding could lead to under- or over-estimation of the estimated 
associations. In addition we were unable to examine the mechanisms (i.e. supervision, safety of environment) through which maternal depression/anxiety may affect child injury risk.

\section{Comparison with previous studies}

There are no directly comparable studies that have examined child injury rates during episodes of maternal depression/anxiety, as most existing studies have identified mothers with depression using single measures of depression symptoms,[3-5] or identified a group of mothers with chronic depressive symptoms.[3 4] For example, using a large cohort of mothers and children from England, O'Connor et al demonstrated a $29 \%$ increased odds of burns/scalds among children aged 15-24 months among mothers identified as having depressive symptoms at 21 months (odds ratio 1.29, $95 \% \mathrm{Cl} 1.01-1.64),[5]$ which compares to our finding of a $31 \%$ higher rate of child burns during maternal depression episodes, and a 53\% higher rate during maternal depression with anxiety episodes. While we have not been able to examine mechanisms explaining the link between maternal depression and child injuries, existing literature suggests several potential mechanisms. Firstly, the nature of depressive symptoms (e.g. low mood, loss of interest, fatigue, poor concentration) may affect the mother's responsiveness to the child, ability to respond to environment, and ability to maintain intense supervision.[2 2425$]$ Secondly, there is some evidence to suggest maternal depression is associated with child behavioural disorders,[25] which can increase child injury risk. Finally, some studies have demonstrated reduced safety practices among depressed mothers (e.g. use of car seats, smoke alarms, cupboard safety catches),[26 27] particularly among those with greater symptom severity and chronicity.[26]

To our knowledge, no previous studies have considered the association between comorbid depression with anxiety and childhood injuries. We found that rates of child poisonings, fractures and burns were higher in episodes of depression with anxiety compared to episodes of depression or anxiety alone. The clinical interpretation of this is not straightforward as there are no standardised 
or consistently used diagnostic tests or definitions for diagnosing depression/anxiety in UK primary care. This finding could relate to depression with anxiety episodes indicating more chronic and severe disease; reflected in the longer median duration of these episodes compared to depression episodes alone, and that these episodes more commonly included a hospitalisation (supplementary file 2). This would be consistent with previous studies demonstrating greater child injury risk amongst mothers with persistent and severe depressive symptoms.[3 4] An alternative explanation could be that mothers experiencing symptoms of both depression and anxiety may be more likely to seek medical attention in the event of an injury than mothers who experienced depression alone as a result of symptoms of anxiety.

\section{Conclusions}

Increased rates of child poisonings, fractures and burns during maternal depression/anxiety episodes highlights the importance of prompt diagnosis and treatment for maternal depression/anxiety, as effective management of maternal depression/anxiety may have beneficial effects for both the mother's wellbeing and child injury risk. Clinicians involved in the care of families (e.g. GPs, health visitors, paediatricians) should consider providing safety advice and referral to home safety schemes,[28 29] where these are available. The association between maternal depression/anxiety and child injuries could be further substantiated through studies assessing the impact of treatment for depression/anxiety on child injury risk, and through the use of other methods such as the self-controlled case series analysis, a within person design that accounts for many confounding variables that are otherwise difficult to control for. 


\section{What is already known on this subject}

- Maternal depression has been linked to reduced use of safety measures (e.g. child car seats, working smoke alarms).

- Existing studies demonstrating greater injury risk among children of depressed mothers have predominantly relied on maternal reporting of injury outcomes, and focused on depression alone.

\section{What this study adds}

- Rates of medically recorded child poisonings, fractures and burns were increased during episodes of maternal depression and/or anxiety in a cohort of over 200,000 mother-child pairs from England.

- Poisoning, fracture and burn rates were highest during episodes where mothers were diagnosed with both depression and anxiety.

- Prompt identification and treatment of maternal depression and/or anxiety, and provision of safety advice may reduce child injury risk. 
Funding: This paper presents independent research funded by the National Institute for Health Research School for Primary Care Research (NIHR SPCR) and The University of Nottingham.

Disclaimer: The views expressed are those of the author(s) and not necessarily those of the NIHR, the NHS or the Department of Health.

Conflict of interests: The authors declare that they have no conflict of interest.

Ethical approval: This study was approved by the Independent Scientific Advisory Committee for the Medicines and Healthcare products Regulatory Agency, February 2014 (protocol 14_025R).

Authors' Contributions: All authors were involved in the conception and design of the study. RB undertook the analysis and drafted the manuscript. All authors contributed to interpreting the findings and revising the manuscript. 


\section{REFERENCES}

1. Howard LM, Molyneaux E, Dennis CL, et al. Non-psychotic mental disorders in the perinatal period. Lancet. 2014;384(9956):1775-88 doi: 10.1016/S0140-6736(14)61276-9.

2. Stein A, Pearson RM, Goodman SH, et al. Effects of perinatal mental disorders on the fetus and child. Lancet. 2014;384(9956):1800-19 doi: 10.1016/S0140-6736(14)61277-0.

3. Phelan K, Khoury J, Atherton $\mathrm{H}$, et al. Maternal depression, child behavior, and injury. Inj Prev. 2007;13(6):403-8 doi: 10.1136/ip.2006.014571.

4. Schwebel DC, Brezausek CM. Chronic maternal depression and children's injury risk. J Pediatr Psychol. 2008;33(10):1108-16 doi: 10.1093/jpepsy/jsn046.

5. O'Connor TG, Davies L, Dunn J, et al. Distribution of accidents, injuries, and illnesses by family type. ALSPAC Study Team. Avon Longitudinal Study of Pregnancy and Childhood. Pediatrics. 2000;106(5):E68.

6. Public Health England. Reducing unintentional injuries in and around the home among children under five years. London: Public Health England, 2014.

7. Peden M, Oyegbite K, Ozanne-Smith J, et al. World report on child injury prevention. Geneva: World Health Organisation, 2008.

8. Department of Health. Annual Report of the Chief Medical Officer 2012, Our Children Deserve Better: Prevention Pays. London: Department of Health, 2013.

9. Orton E, Kendrick D, West J, et al. Independent risk factors for injury in pre-school children: three population-based nested case-control studies using routine primary care data. PLoS One. 2012;7(4):e35193 doi: 10.1371/journal.pone.0035193.

10. Yamaoka Y, Fujiwara T, Tamiya N. Association Between Maternal Postpartum Depression and Unintentional Injury Among 4-Month-Old Infants in Japan. Matern Child Health J. 2016;20(2):326-36 doi: 10.1007/s10995-015-1832-9. 
11. Herrett E, Gallagher AM, Bhaskaran K, et al. Data Resource Profile: Clinical Practice Research Datalink (CPRD). Int J Epidemiol. 2015;44(3):827-36 doi: 10.1093/ije/dyv098.

12. Benson T. The history of the Read Codes: the inaugural James Read Memorial Lecture 2011. Informatics in primary care. 2011;19(3):173-82.

13. Rait G, Walters K, Griffin M, et al. Recent trends in the incidence of recorded depression in primary care. Br J Psychiatry. 2009;195(6):520-4 doi: 10.1192/bjp.bp.108.058636.

14. Walters K, Rait G, Griffin M, et al. Recent trends in the incidence of anxiety diagnoses and symptoms in primary care. PLoS One. 2012;7(8):e41670 doi: 10.1371/journal.pone.0041670.

15. Baker R, Tata $L$, Kendrick D, et al. Identification of incident poisoning, fracture and burn events using linked primary care, secondary care and mortality data from England: implications for research and surveillance. Inj Prev. 2016;22(1):59-67 doi: 10.1136/injuryprev-2015-041561.

16. Injury Observatory for Britain and Ireland. Serious injury inpatient analysis specification for the Injury Observatory for Britain and Ireland. 2011.

http://www.injuryobservatory.net/analysis-of-inpatient-admissions-data-for-serious-injury/.

17. Cryer C, Langley J, Stephenson S. Developing valid injury outcome indicators. A report for the New Zealand injury prevention strategy. Dunedin, New Zealand: University of Otago, 2004.

18. Woodman J, Freemantle N, Allister J, et al. Variation in recorded child maltreatment concerns in UK primary care records: a cohort study using The Health Improvement Network (THIN) database. PLoS One. 2012;7(11):e49808 doi: 10.1371/journal.pone.0049808.

19. Ban L, Gibson JE, West J, et al. Impact of socioeconomic deprivation on maternal perinatal mental illnesses presenting to UK general practice. Br J Gen Pract. 2012;62(603):e671-8 doi: 10.3399/bjgp12X656801.

20. Ban L, Gibson JE, West J, et al. Association between perinatal depression in mothers and the risk of childhood infections in offspring: a population-based cohort study. Bmc Public Health. 2010;10 doi: Artn 799

10.1186/1471-2458-10-799. 
21. Dave S, Petersen I, Sherr L, et al. Incidence of maternal and paternal depression in primary care: a cohort study using a primary care database. Archives of pediatrics \& adolescent medicine. 2010;164(11):1038-44.

22. Andersson NW, Goodwin RD, Okkels N, et al. Depression and the risk of severe infections: prospective analyses on a nationwide representative sample. Int J Epidemiol. 2016;45(1):131-9 doi: 10.1093/ije/dyv333.

23. Ablewhite J, Peel I, McDaid L, et al. Parental perceptions of barriers and facilitators to preventing child unintentional injuries within the home: a qualitative study. BMC Public Health. 2015;15:280 doi: 10.1186/s12889-015-1547-2.

24. Lovejoy MC, Graczyk PA, O'Hare E, et al. Maternal depression and parenting behavior: a metaanalytic review. Clin Psychol Rev. 2000;20(5):561-92.

25. Phelan KJ, Morrongiello BA, Khoury JC, et al. Maternal supervision of children during their first 3 years of life: the influence of maternal depression and child gender. J Pediatr Psychol. 2014;39(3):349-57 doi: 10.1093/jpepsy/jst090.

26. Conners-Burrow NA, Fussell JJ, Johnson DL, et al. Maternal low- and high-depressive symptoms and safety concerns for low-income preschool children. Clinical pediatrics. 2013;52(2):171-7.

27. McLennan JD, Kotelchuck M. Parental prevention practices for young children in the context of maternal depression. Pediatrics. 2000;105(5):1090-5.

28. National Institute for Health and Care Excellence. Unintentional injuries in the home: interventions for under 15s. London: NICE PH30, 2010.

29. Kendrick D, Young B, Mason-Jones AJ, et al. Home safety education and provision of safety equipment for injury prevention. Cochrane Database Syst Rev. 2012;9:CD005014 doi: 10.1002/14651858.CD005014.pub3. 
Fig 1 Illustration of maternal depression/anxiety episodes as a time-varying exposure.

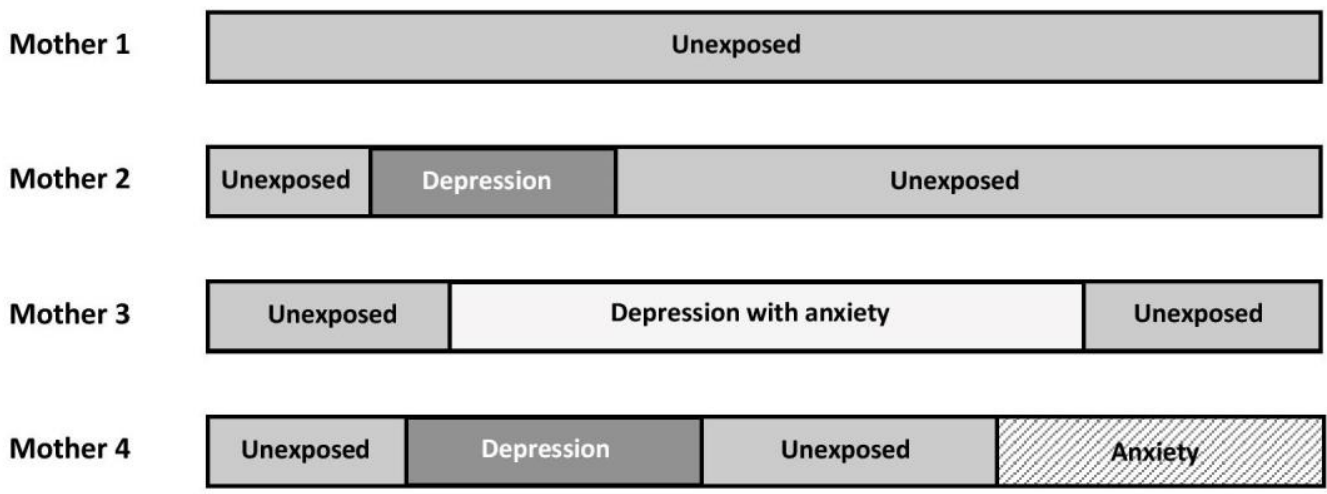

Footnote to figure: For those mothers with no records for depression and/or anxiety in their medical records, all of their follow-up time was classified as unexposed. 